\title{
Tangence
}

\section{Homo loquax... ou Sésame, divertis-moi !}

\section{Hugues Bonenfant}

Numéro 52, septembre 1996

Tours et détours du romanesque : Minuit aujourd'hui

URI : https://id.erudit.org/iderudit/025921ar

DOI : https://doi.org/10.7202/025921ar

Aller au sommaire du numéro

Éditeur(s)

Tangence

ISSN

0226-9554 (imprimé)

1710-0305 (numérique)

Découvrir la revue

Citer cet article

Bonenfant, H. (1996). Homo loquax... ou Sésame, divertis-moi ! Tangence, (52),

113-115. https://doi.org/10.7202/025921ar d'utilisation que vous pouvez consulter en ligne.

https://apropos.erudit.org/fr/usagers/politique-dutilisation/ 


\section{Homo loquax... ou Sésame, divertis-moi !* Hugues Bonenfant}

$\mathrm{Au}$ commencement était le Verbe. Il était dieu en toute sa splendeur. De neuf à cinq, du lundi au vendredi, cette semainelà, Il travailla fort afin de tout créer. Le sixième jour, le Verbe insuffla la vie dans l'Homme. Une femme et un homme, l'Histoire pouvait alors commencer. À l'ombre des dieux, ce septième jour, dit jour du repos, allait permettre à l'Homme de créer à son tour. L'histoire des créations humaines est longue...

Entre les trois Critiques de Kant, les pamphlets incisifs de Voltaire et les chroniques littéraires de Jean Basile, il semble que nos âges modernes aient développé une créature nouvelle: la "pop-critique" - et sa dérivée nécessaire, le pop-critique. De prime abord, car il s'agit d'une œuvre humaine, elle s'installe aux côtés des autres labeurs toujours aussi humains (biologie, peinture, mathématique, hockey, escalade, théologie, musique...). Cependant, bien que tous les labeurs créent quelque chose, ce quelque chose n'est pas toujours un *produit. Dans les milieux culturels (entendre artistiques), les artistes sont considérés comme les vrais créateurs car ils engendrent des choses à partir d'éléments primaires alors que les diffuseurs, les facilitateurs et autres intermédiaires en tout genre, chargés d'acheminer la création produite au vu et au su d'un public, ne le sont généralement pas.

Le cas du critique et plus encore celui du pop-critique n'est pas aussi clair. En effet, en tenant un "discours-sur", le critique use à son tour du savoir-faire de Merlin et crée. Son travail, toutefois, d'une facture sobre ou passionnée, sera toujours en retrait de l'autre et tendra à l'analyse sérieuse d'une ouvre et à sa synthèse dans la genèse du genre et dans le contexte sociopolitico-artistique environnant. Il est la loupe qui aide à voir; l'attention de son audience ne doit pas s'arrêter sur la lentille. Le pop-critique, croirait-on, fait sensiblement le même effort. Faux! Il est assez manifeste qu'il n'en va pas de la sorte, particulière-

- Ce texte s'est classé au troisième rang de la catégorie - texte de réflexion * du concours : Le printemps des revues. Tangence offre ses félicitations au lauréat. 
114

ment dans les médias parlés - peut-être l'écrit fournit-il un support plus adéquat à la réflexion critique que la trop spontanée expression orale? Une chose est sûre, en principe, cette césure par le "pop" ne devrait pas exister. Il y a détournement de l'œuvre critiquée.

La scission, pensons-nous, prend sa source dans l'utilisation que chacun fait du langage: Bien que tous deux effectuent un discours-sur, l'objet sur lequel il porte est fort différent. De fait, le critique, par la magnanimité de son verbe, étreint son propre langage et celui de l'artiste comme un moyen dans la fonctionnalité expressive *quelqu'un/quelque chose/quelqu'un d'autre . En prenant le point de vue du "quelque chose créé", il tente simplement de magnifier la présence ou l'absence de certains corrélats ayant lieu entre les intéressés actuels ou potentiels. Le popcritique, ne le nions pas, prend aussi le motif de l'œuvre d'art pour discourir, mais son verbe se substitue à celui de l'artiste, en stigmatise la syntaxe et prend sa propre grammaire pour fin du langage. Feignant d'épiloguer (la critique est essentiellement $e p i-\log o s$, il raconte plutôt son rapport personnel normatif entretenu avec le *-cin de cette * œuvre-ci". Il va de soi que la consommation d'un produit régisse sa pratique et qu'il délaisse l'horizon de l'ouvre. Il discourt ainsi surtout de sa création langagière particulière, avec son lọt de mots précieux, parce qu'empruntés au champ de la critique, et de lieux communs, parce que d'abord voyeur.

Évidemment, le critique aussi goûte par sa propre bouche, voit avec l'intimité de ses yeux et parle sa langue distinctive puisqu'il est de même homo sapiens: afin de connaitre, il faut "déguster", ce qui est bien subjectif. Toutefois, il sait faire la part entre une forme locutoire qui peut susciter l'intérêt et le simple fait de faire l'intéressant. S'il est apte à opérer une critique, c'est qu'il peut d'abord, semble-t-il, aimer l'œuvre sur laquelle il se penche (l'amour n'est-il pas l'accueil de l'autre en tant qu'autre plutôt que, a priori, sa transformation en éprouvette à désirs, phantasmes, aspirations et humeurs?). Le pop-critique s'interdit cette "camaraderie" maîtresse de tout voir critique: il veut parler de ce qu'il reconnaît avant même de le connaître. Mais sans doute a-t-il quelques obscurs impératifs l'empêchant à "l'ascèse ${ }_{\text {n... }}$

Pour autant, ne jugeons pas le pop-critique d'épigone; entendons plutôt son statut pareillement à celui de l'artiste, 
puisqu'il n'épilogue pas vraiment. Alors, que crée-t-il? - Rien! Son art est virtuel, il met en scène son talent créateur dans un théâtre de procuration: l'œuuve critiquée lui est prétexte au déploiment de son "professionnalisme". Son verbe est loquacité: il voudrait éclairer la lumière! Que crée-t-il? - Une lumineuse distraction. Mais une bien fumeuse distraction dans la mesure où le pop-critique s'approprie la tribune du critique afin d'y faire son show. Nous ne dénions pas ses qualités stylistiques et esthétiques (et moins encore nous ne le confondons avec les commères d'une certaine presse), nous questionnons simplement l'utilisation quasi frauduleuse qu'il fait d'un contexte qui ne devrait pas être le sien. En ce sens aussi, est-il donc beaucoup plus artiste qu'ịl ne le prétend.

Si le pop-critique est artiste, son discours critique devrait être reçu avec un grain de sel à défaut d'apparaître franchement louche. Il requerrait même un désaveu par les critiques et, qui plus est, une sévère critique. Cette apathie de l'association des critiques (car il doit sûrement y avoir un quelconque syndicat traçant les lignes d'un etbos du critique) devrait sérieusement être secouée, au risque de quoi le profane, parce qu'il est amateur et n'ose donc pas parler, pourrait devenir plus éclairé que le professionnel. À moins, bien sûr, que les critiques eux-mêmes rêvassent justement de sbowbiz. Ainsi, comme le chantait l'autre, if the hat fit, let them wear it. Mais peut-être n'est-ce pas assez ludique... Je me tais. 